\title{
Implementation of a Novel Return-to-Ride Concussion Management Policy for Collegiate Hunter/Jumper Equestrian Athletes
}

\author{
Devon Serrano, DAT, LAT, ATC, NREMT* \& Velyn Wu, MD $\dagger$ \\ *Sweet Briar College, Sweet Briar, VA; †University of Florida, Gainesville FL
}

\section{ABSTRACT}

A concussion return-to-participation protocol specific to equestrian is critical in the safe return of athletes to their respective discipline. When the care of the hunter/jumper equestrian teams became the responsibility of the Sports Medicine staff at Sweet Briar College, a return-toparticipation concussion management policy was needed to ensure the safety of the equestrian student-athletes. A quality-improvement project focusing on the development of a "Return-to-Ride" protocol was started in the fall semester of 2016. The Sports Medicine staff collaborated with the Sweet Briar College riding center to create and ensure compliance of the protocol. The intended aim of developing this protocol was to create a guideline for concussion management of the equestrian student-athlete that would standardize care across sports and between providers. At the time of this quality improvement cycle, no specific concussion management protocol had been adopted or approved for any discipline of equestrian. Due to the differences between equestrian sports, changes would be need to be made in order to best serve the athlete(s) affected. Using a traditional five-day return-to-play program as an example, the Returnto-Ride (RTR) protocol is seven days of gradual riding for equestrian athletes. This protocol accounts for the specific physical demands and vestibular disruptions associated with equestrian. This Plan, Do, Study, Act (PDSA) cycle was conducted during the fall semester of 2016 to the fall semester of 2019. The purpose of this PDSA cycle was to provide athletic trainers and other healthcare providers with insight on the development and outcomes of a concussion return to participation protocol for equestrian athletes.

Key Phrases

Policy and procedure development, risk management and mitigation, professional standards

\section{Correspondence}

Dr. Devon Serrano, Sweet Briar College, 134 Chapel Rd., Sweet Briar, VA 24595.

E-mail: dserrano@sbc.edu

Twitter: @devonserrano

\section{Full Citation}

Serrano D \& Wu V. Implementation of a Novel Return-toRide Concussion Management Policy for Collegiate Hunter/Jumper Equestrian Athletes. Clin Pract Athl Train. 2020;3(2): 15-30.

https://doi.org/10.31622/2020/0002.4.

Submitted: October 15, 2019 Accepted: June 14, 2020

\section{CURRENT MODEL}

In 2017, the Sport Science Institute (SSI) of the

National Collegiate Athletic Association (NCAA) released updated recommendations on concussion safety management in intercollegiate athletics. ${ }^{1}$ The Concussion Safety Protocol Checklist and Diagnosis and Management of Sport-Related Concussion Best Practices interassociation consensus documents serve as the standard to which colleges and universities associated with the NCAA hold their concussion safety management programs. ${ }^{1}$ Athletic trainers often serve as the management personnel of student-athletes with concussions from initial evaluation to return to activity. $^{2}$ In order to best serve athlete populations, concussion management recommendations state that Return-to-Play (RTP) protocols must include sport-specific exercise. ${ }^{1}$ In August 2016, equestrian was granted full access to the Sports Medicine Clinic at Sweet Briar College. The Sports Medicine staff had limited knowledge regarding the demands of the sport, especially when it came to sport-specific activities for concussion management. A RTP protocol specific to equestrian did not exist.

Presently, no aspects of equestrian are considered champion sports in the NCAA, though it has been considered an emerging sport for women at Division I and II since 2002.3-5 As of September 2019, the NCAA Committee on Women's Athletics voted in favor of a proposal to add equestrian to the NCAA Emerging Sports for Women program at the Division III level. ${ }^{5} \mathrm{~A}$ vote by the Division III membership on the proposal, conducted in January 2020, was narrowly defeated. 5 In order to be considered a champion sport and have 
recognized competitive seasons that end with a championship, 40 programs must declare intent to have a varsity program. ${ }^{3}$ For collegiate programs, the options for competition associations include the Intercollegiate Horse Shows Association (IHSA) and National Collegiate Equestrian Association (NCEA).6.7 At the time of publication, membership in the NCEA extends over all three NCAA divisions with 17 schools in Division I, five in Division II and three in Division III. ${ }^{8}$ The IHSA membership extends to 48 states and Canada with over 10,000 participating student-athletes from 577 member schools. 6 No specific concussion management protocol has been adopted or approved by either organization, leaving each member school to manage concussions individually. 6,7 The availability of a concussion management protocol specifically for equestrians would allow for a consistent level of care among member schools within an association.

The purpose of the following document is to describe the use of a quality improvement process in developing an equestrian-specific Return-toRide (RTR) concussion management protocol for a collegiate equestrian program. The aim was to develop and implement a guideline for concussion management of the equestrian student-athlete that would standardize care provided by all members of the sports medicine team to the same level given to all other existing sports managed by the sports medicine department. The process for the development and implementation of a sport-specific concussion management protocol, challenges and barriers and outcomes will be discussed.

\section{PDSA CYCLE}

\section{Plan}

The first step of the development phase was determining individuals who would be critical in a successful creation of a protocol. The primary writer on the protocol in this instance was the Director of Sports Medicine for Sweet Briar, with input and direction from the Team Physician for

Copyright (C) by Indiana State University
Sweet Briar Athletics and the Director of Riding at the College.

Equestrian access to sports medicine services varies on the institution. According to the IHSA 2018-2019 Rulebook and NCEA Rulebook (revised in February 2019), a qualified medical professional must be on site for all schooling sessions and the entire length of a performance or show. ${ }^{10,12}$ A qualified medical professional is listed as a certified and/or licensed emergency medical technician, paramedic, physician or nurse who is trained in pre-hospital trauma. ${ }^{10,12}$ At the collegiate level, access to sports medicine services vary based on the school's distinction of the team, whether it be club or varsity status. Further research and advocacy is currently being conducted to propose the creation of a standard by which collegiate equestrian teams receive access to sports medicine services and the allowance of athletic trainers to be deemed qualified medical professionals by IHSA and NCEA standards.

Researching the specific demands, physical and mental, is needed for the creation of sport-specific policies. Although created and initially implemented using hunter/jumper athletes, the goal of the protocol was to allow for adjustments to fit the needs of all equestrian athletes based on the demands of the sport. This included development of skill session parameters for traditional five-phase policies. ${ }^{1}$ There were several physical demands that needed to be met in order to have the protocol be successful. Hunter/jumper equestrian is about the relationship between the rider and the horse. The two are teammates and the success of one is equally dependent on the success of the other. ${ }^{9}$ Due to the changes in pace (walk, trot, canter and/or gallop) and height variations, there are also vestibular disruptions that must be accounted for. Jumps in collegiate competition in the NCEA and IHSA can range from two feet six inches to three feet six inches in height. ${ }^{8,10}$ Theses demands on the rider were discussed with the Sports Medicine staff by

\footnotetext{
Clinical Practice in Athletic Training
} Volume 3 - Issue 2 - June 2020 
the Riding Center staff, including physical demands (particularly on the hip, back, shoulder and lower leg) and vestibular disruptions throughout the pace and height variances. 9,11

\section{Do}

The Sweet Briar College Return-to-Ride protocol was developed for hunter/jumper equestrian athletes in the fall semester of 2016 . The protocol (Appendix A), was created in conjunction with the Director of the Harriet Howell Rogers Riding Center at Sweet Briar College in Sweet Briar, Virginia. The protocol was designed to slowly increase the rider's control over the horse, cardiovascular intensity, musculoskeletal involvement and changes in vestibular disruption. The purpose of the protocol was to outline an equestrian-specific return to participation for student-athletes competing on the College's competitive equestrian teams. It also served as a way to build a rapport and relationship with the College's equestrian program's student-athletes and coaches. Prior to the 2016-2017 academic year, there had been no significant interaction between the equestrian program and the sports medicine team.

The RTR protocol was designed in compliance with the NCAA Interassociation Consensus: Diagnosis and Management of Sport-Related Concussion Practices. ${ }^{13}$ At the initial conception of the RTR protocol, a five-phase policy was proposed to the Director of Riding at Sweet Briar (Table 1) after discussing with the Director the demands placed on equestrian athletes as they return after any injury. Table 2 outlines the sections present in the RTR policy and procedure document that were developed using best-practice guidelines. The proposed protocol followed the standard fivephase outline as expected by the NCAA. ${ }^{1}$ The purpose of the original five-phase protocol was to serve an outline for all three members of the creation team to follow and work from as well as giving the Director of Riding an idea as to the types of activities that might be needed in a final version of a protocol.

Copyright (C) by Indiana State University All rights reserved. ISSN Online 2577-8188
The decision to extend the protocol from five days to seven days was jointly made by the Director of Sports Medicine, the team physician, and the Director of Riding. One of the concerns when a five-phase protocol was proposed was that the athlete might not have enough time to gain confidence on the horse and manage the fine and gross motor control demands put on the body as well as vestibular disruptions. The extension of the RTR protocol to seven days also accounted for the addition of the horse as part of the studentathlete's full participation in equestrian events. Because the horse is a significant part of the sport, it was important to involve use of a horse in the protocol to allow for the student-athlete to work on gaining control in gradual monitored steps. A RTR protocol completion sheet was created with the return to ride phases and places for instructor sign-off after completion of each phase. This sheet was created to track rider progression throughout the protocol.

The RTR protocol consists of seven days of gradual increases in riding under the participation direction of a coach and medical direction of a certified athletic trainer. Athletes are able to proceed to the next phase if they are asymptomatic at the satisfaction of the current phase and the subsequent 24 hours. $^{2}$ If symptoms occur during activity, the athlete is removed from activity and instructed to rest for 24 hours prior to considering starting from the previous level that did not produce symptoms. Symptoms that were exacerbated at this progression stage must dissipate prior to attempting the previous stage. Per the recommendation of the National Athletic Trainers' Association (NATA) position statement, final clearance for full participation following completion of the protocol is required from a medical doctor. ${ }^{2}$

During the creation of the policy and procedure, several audiences had to be considered including student-athletes, coaches, horse trainers, and stakeholders. As access to sports medicine services varies across secondary school, collegiate, and 
Table 1. Original Proposed Five-Phase Return-to-Ride Protocol
Phase 1: Light
20 minutes stationary bike at $70 \%$ maximum heart rate
aerobic exercise
Phase 2: Moderate
aerobic exercise
Interval bike ride: 10 sets of 30 second sprints/30 seconds recovery
Body weight circuit: Squats/Push-Ups/Sit-Ups: Three sets of 20 each
60 yard shuttle run
Phase 3: Sport-
Specific Exercises
Plyometric Circuit (examples): 10 yard bounding/ 10 medicine ball throw $/ 10$
vertical jumps; three times each
15 minutes of walking on a horse with trotting (based on the rider's abilities)
Phase 4: Full-
contact practice
Phase 5
Limited participation in full contact practice and monitoring of symptoms
Inclusion of jumping small obstacles (based on the rider's abilities)
Full participation in practice

Table 2. Sections of the Return to Ride Policy and Procedure Document

\begin{tabular}{|c|c|}
\hline Education & $\begin{array}{l}\text { Mandatory educational session for all student-athletes and coaches, } \\
\text { informational document provided to all student-athletes and coaches, } \\
\text { acknowledgement of concussion understanding for all student-athletes and } \\
\text { coaches }\end{array}$ \\
\hline $\begin{array}{l}\text { Pre-Participation } \\
\text { Assessment }\end{array}$ & $\begin{array}{l}\text { Completed annually for all student-athletes and includes the competition of the } \\
\text { most current version of the Sport Concussion Assessment Tool (SCAT) with full } \\
\text { Balance Error Scoring System (BESS) test. All history questions must be } \\
\text { completed as part of the SCAT assessment. }\end{array}$ \\
\hline Post-Concussion & Immediately upon suspicion of concussion: \\
\hline \multirow[t]{6}{*}{ Management } & - Removal from participation \\
\hline & $\begin{array}{l}\text { - Completion of SCAT test with balance (BESS or tandem walk as } \\
\text { available) }\end{array}$ \\
\hline & - Evaluation of head and cervical spine \\
\hline & - Initiation of Emergency Action Plan if necessary \\
\hline & - Serial evaluation and monitoring for deterioration post-injury. \\
\hline & - Home instructions with discharged from medical care \\
\hline Return to Academics & $\begin{array}{l}\text { A four-phase stepwise progression that works to allow student-athletes to } \\
\text { increase in their workload and class attendance safely with multiple evaluations } \\
\text { with the managing athletic trainer with communication with members of the } \\
\text { academic community necessary for the student-athlete's success. }\end{array}$ \\
\hline Return to Activity & $\begin{array}{l}\text { Utilized in initial recovery, return to learn (RTL) progression and return to } \\
\text { play/ride progression }\end{array}$ \\
\hline Return to Play & $\begin{array}{l}\text { Termed "Return to Ride" for Equestrian athletes in this policy and procedure. } \\
\text { Appendix A. }\end{array}$ \\
\hline
\end{tabular}

private settings, it is important to educate coaches and horse trainers on the impact of concussions and the importance of progressionbased concussion management in the return of a student-athlete to activities of daily living, academics and riding participation. ${ }^{13}$ This also serves as an opportunity to educate stakeholders on the value of athletic trainers and their possible collaboration when working with student-athletes who compete in equestrian sports. The final policy and procedure document as updated in September 2019 (Appendix A) outlines the purpose of concussion management for student-athletes as well as the full policy for pre-participation examinations, return-to-learn (RTL) progression, and RTR policy (Table 3). 
Table 3. Seven-Day Return-to-Ride Protocol

\begin{tabular}{|c|c|}
\hline Phase 1 & $\begin{array}{l}\text { - Mount/Dismount/Lead in } \\
\text { Hand/Walk Undersaddle } \\
\text { (mounted) } \\
\text { - Mount/Dismount, lead for five } \\
\text { minutes (Complete two times) } \\
\text { - Mount, walk undersaddle for } 15 \\
\text { minutes } \\
\text { - Dismount and put the horse away }\end{array}$ \\
\hline Phase 2 & $\begin{array}{l}\text { - Mount and walk for } 10 \text { minutes } \\
\text { - Trot two laps around the indoor } \\
\text { arena } \\
\text { - Walk five minutes } \\
\text { - Trot two laps around the indoor } \\
\text { arena } \\
\text { - Walk for } 10 \text { minutes } \\
\text { - Dismount and put the horse away }\end{array}$ \\
\hline Phase 3 & $\begin{array}{l}\text { - Mount and walk for } 10 \text { minutes } \\
\text { - Trot four laps around the indoor } \\
\text { arena } \\
\text { o Walk two minutes } \\
\text { - Trot four laps around the indoor } \\
\text { arena } \\
\text { - Walk for } 10 \text { minutes } \\
\text { - Dismount and put the horse away }\end{array}$ \\
\hline Phase 4 & $\begin{array}{l}\text { - Mount and walk for } 10 \text { minutes } \\
\text { - Trot four laps around the indoor } \\
\text { arena } \\
\text { O Walk two minutes } \\
\text { - Trot four laps around the indoor } \\
\text { arena } \\
\text { - Walk for one minute } \\
\text { - Canter a lap in each direction } \\
\text { - Walk for } 10 \text { minutes } \\
\text { - Dismount and put the horse away }\end{array}$ \\
\hline Phase 5 & $\begin{array}{l}\text { - Mount and walk for } 10 \text { minutes } \\
\text { - Work at the trot and canter for } \\
\text { - } 15 \text { minutes with periods of walk } \\
\text { - Dismount and put the horse away }\end{array}$ \\
\hline Phase 6 & $\begin{array}{l}\text { - } \quad \text { Repeat Phase } 5 \\
\text { - } \quad \text { Add jumping small obstacles }\end{array}$ \\
\hline Phase 7 & $\begin{array}{l}\text { - Full participation in practice or } \\
\text { lesson without restrictions }\end{array}$ \\
\hline
\end{tabular}

\section{Study}

The RTR protocol was created, developed and implemented at the beginning of the Fall 2016. The first equestrian related concussion occurred in Spring 2017. To determine how the RTR protocol compared to the RTP protocol, the following items were collected:

- Date of Injury

- Date of Evaluation

- Number of Days from Injury to RTL phase 4 (RTL 4)

- Dates each phase of the student's respective return to participation protocol was completed

- Number of days from the date of injury to date of protocol completion

All the collected dates were placed in a password protected spreadsheet and updated daily throughout the athlete's recovery. The average number of days from injury to RTL4 and from injury to concussion resolution were collected for all athletes in sports managed by the Sweet Briar College Sports Medicine Department. This included athletes who completed any of the three concussion return to participation protocols (RTP, RTR or a combination protocol). Any observations were documented on the athletes' concussion evaluation for that day and/or in the notes section of the athlete's injury in the electronic medical record system.

At the time of submission, the protocol had been completed a total of 16 times with collegiate hunter/jumper equestrian athletes. As with all student-athletes, they were required to also complete their four-phase RTL protocol prior to the RTR protocol. Since the introduction of the RTR protocol in September 2016, a total of 85 return to participation protocols for all sports at Sweet Briar college were completed (69 RTP and 16 RTR) (Figure 1). A total of seven NCAA varsity programs and two competitive equestrian teams used the appropriate return to activity protocol. Five concussion management cases (four RTP and one RTR) were not included in this analysis 
because the return to participation protocol was not completed for reasons such as medical withdrawal, athlete non-adherence, athlete transfer to another institution and graduation from the institution. Concussions included in this analysis were categorized as incoming (occurred prior to enrollment at Sweet Briar College), athletic mechanism of injury or non-athletic mechanism of injury.

In this analysis, the average number of days lost to concussion recovery was followed (Figure 2). This was defined as the time frame from the date of injury evaluation to the date of full athletic return. It is important to note that the averages from the Fall 2018 semester were higher due to several protocols implemented over Winter Break and being completed at the start of the Spring 2019 semester. In both the Spring 2018 and Spring 2019 semesters, protocols were delayed due to Spring Break and were completed when the student-athlete(s) returned to campus. Overall as of September 30, 2019 the seven-day RTR protocol presented similar averages of days lost to concussion as its five-day RTP counterpart. Due to the additional two days in the RTR protocol, it was surprising to see that the averages of days lost was as close as they were.

A major success was the quick adaption of the protocol by the equestrian staff. The coaches and instructors were open to the use of the protocol and served as advocates for the athletes if an injury (concussion or other) occurred as well as encouraging them to seek medical attention. They were receptive to education relative to concussions and were willing to assist in concussion management when needed and necessary.

As in any setting with a new possible policy, there were challenges to implementation of the new concussion policy with procedures. The RTR protocol was designed for use with collegiate hunter/jumper equestrian student-athletes who had limited to no prior access to an athletic trainer either at the institution or at their high school and/or private barn. The initial challenge was working with the student-athletes to gain their buy-in into being able to use an athletic trainer, not just for concussion management, but also for general athletic health care. Cooperation from the student-athletes began with an introductory meeting at the beginning of the year to introduce the athletic trainer and explain offered services with locations and available times. This introduction is now offered annually as part of the onboarding experience for both new and returning student-athletes. Another step towards buy-in of the policy was meeting with studentathletes at the barn and campus arenas. This was a time for both the athletic trainer and studentathletes to ask questions. This allowed for the athletic trainer to speak with the coaching staff and build relationships with them as to how to best utilize the athletic trainer for their student-athletes. At the beginning of the research phase of writing this protocol, the majority of student-athletes were very open to explaining the sport of hunter/jumper equestrian and the psychological connect they have with the barn, as well as the importance of the barn to their personal identify.

A second challenge was that no specific training with the sports medicine team or equestrian coaches was conducted on the implementation of the protocol. The athletic trainer met with the equestrian coaches to discuss the new protocol, athlete evaluations, completion of phases and how to respond if an athlete reports symptoms at any point (during recovery or return to ride phase).

\section{Act}

For clinicians in settings where they are building new relationships, it is important to learn about the sport they are working with. This includes understanding the physical competitive aspects of the sport as well as the psyche of the athletes and how their sport impacts their lives. In terms of understanding the sport, it is important that policies reflect sport participation and serve as a 
Figure 1. Number of Return to Participation Protocols Completed from August 2016 to September 2019

\begin{tabular}{lcc} 
Academic Term & $\begin{array}{c}\text { Number of RTP Protocols } \\
\text { Completed }\end{array}$ & $\begin{array}{c}\text { Number of RTR Protocols } \\
\text { Completed }\end{array}$ \\
\hline Fall 2016 & 22 & 0 \\
Spring 2017 & 7 & 5 \\
Fall 2017 & 20 & 3 \\
Spring 2018 & 6 & 1 \\
Fall 2018 & 10 & 4 \\
Spring 2019 & 3 & 2 \\
Fall 2019 (as of September 23, 2019) & 1 & 1 \\
Total Number Completed & 69 & 16 \\
\hline
\end{tabular}

Figure 2. Average Days Lost from Evaluation to Completion of Designated Return to Participation Protocol

\begin{tabular}{lcc}
\hline Academic Term & $\begin{array}{c}\text { Average Days from } \\
\text { Evaluation to RTP 5 }\end{array}$ & $\begin{array}{c}\text { Average Days from } \\
\text { Evaluation to RTR 7 }\end{array}$ \\
\hline Fall 2016 & 20.4 & - \\
Spring 2017 & 16.2 & 16.8 \\
Fall 2017 & 20.7 & 24.3 \\
Spring 2018 & 20.0 & 32.0 \\
Fall 2018 & 48.1 & 21.25 \\
Spring 2019 & 19.0 & 27.0 \\
Fall 2019 (as of September 30, 2019) & 12.0 & 12.0 \\
Average Number of Days Lost & 22.3 & 25.4 \\
\hline
\end{tabular}

guide to clinical practice. This creates a standard for patient care and protects the clinician legally. When creating a new policy and procedure, especially when working with a new program or a program that has had little to no interaction with an athletic trainer, policy development serves as a good opportunity to learn about the sport and build strong relationships with coaches and other stakeholders.

One potential barrier to implementation of the RTR protocol is how the protocol needs to be adjusted when an athlete only rides two to three times per week. A lesson-based schedule can delay the completion of an athlete's protocol so adjustments might be necessary to keep the protocol from being completed over several

Copyright (C) by Indiana State University All rights reserved. ISSN Online 2577-8188 weeks. This barrier can be overcome by working with the equestrian coaches and instructors to allow the athlete to complete supervised rides outside of their designated lesson times.

Another barrier is the skill level of each athlete. With abilities ranging from beginner Walk/Trot up to those able to jump three feet six inches, it is important to make sure the athlete can complete their protocol safely and in their own skill range. In the event an athlete does not canter and/or jump, it may be necessary to modify the protocol phase to make sure the intensity is increased without putting the athlete at risk due to lack of skill. 
An opportunity for further research includes applying the RTR protocol to all equestrian athletes such as those who compete in eventing (dressage, jumpers, and cross country), fox hunting, polo, competitive trail riding, endurance riding, Western Styles (pleasure, reining, cutting, team pinning, working cow horse, trail class, halter), and rodeo events. This protocol was written to serve as a general outline for other competitive sanctions of equestrian so testing and utilization in those sanctions would be needed to determine how effective the policy is in return-toride participation for equestrian athletes. Further research is also needed to determine the psychological effects of concussion on the psyche of equestrian athletes and is currently in the initial stages of development.

\section{Clinical Bottom Line}

Equestrian currently is working towards becoming recognized as an emerging sport within the NCAA and over 10,000 students participate in the sport at the collegiate level annually. Therefore, more research and policy development is needed to ensure that sport-specific policies are created to fit the needs of the athletes competing and participating. Steps in this process include researching statements from the NCAA and sport's governing bodies to determine how one's current policies align with the expectations and standards set forth. It is important to involve important stakeholders in policy creation, editing and implementation. This allows for them to understand the standards expected of the policy as well as give valuable input on needed changes or recommendations. Education and evaluation by staff members and stakeholders are both part of the development and implementation processes. As equestrian continues to rise in status and participation numbers, it is important to develop policies that are sport-specific and align with standards of the sport's governing bodies, NATA, and NCAA. Creation, evaluation and improvement of policies allow for improved

Copyright $($ ) by Indiana State University patient care that is specific to the needs of athletes and their sport.

\section{REFERENCES}

1. National Collegiate Athletic Association. Concussion Educational Resources. Sport Science Institute, National Collegiate Athletic Association, Indianapolis, IN. 2017. Available at: http://www.ncaa.org/sportscience-institute/concussion-educationalresources. Accessed July 2018 and September 2019.

2. Broglio SP, Cantu RC, Gioia GA, Guskiewicz KM, Kutcher J, Palm M, et al. National Athletic Trainers' Association Position Statement: Management of Sport Concussion. J Athl Train. 2014; 49(2):245-265. https://dx.doi.org/10.4085\%2F10626050-49.1.07.

3. National Collegiate Athletic Association. Sports. National Collegiate Athletic Association, Indianapolis, IN. 2017.

4. Stark-Mason R. Still in the Saddle: Equestrian association working to rally support for the sport. NCAA Champion Magazine. December 2015. Available at: http://www.ncaa.org/champion/still-saddle. Accessed July 2018 and September 2019.

5. Stark-Mason, R. Committee on Women's Athletics supports Division III equestrian proposal. National Collegiate Athletic Association. National Collegiate Athletic Association, Indianapolis, IN. 2017.

Available at:

http://www.ncaa.org/about/resources/medi a-center/news/committee-women-s-athleticssupports-division-iii-equestrian-proposal. Accessed September 2019.

6. Intercollegiate Horse Show Association. About: General Information. Intercollegiate Horse Show Association. 2018. Available at: https://www.ihsainc.com/about-us/generalinformation. Accessed July 2018 and September 2019. 
7. National Collegiate Equestrian Association. About. National Collegiate Equestrian Association, Waco, TX. 2018. Available at: https://collegiateequestrian.com/sports/201 9/4/3/ 131987884238679712.aspx. Accessed July 2018 and September 2019.

8. National Collegiate Equestrian Association. Schools. National Collegiate Equestrian Association, Waco, TX. 2018. Available at: https://collegiateequestrian.com/sports/201 9/5/2/EQUEST 0502195449.aspx. Accessed July 2018 and September 2019.

9. Pilato M. A New View: Bringing Sports Medicine to the Equestrian Athletes. American Medical Equestrian Association Safe Riders Foundations News. American Medical Equestrian Association Safe Riders Foundations, Albuquerque, NM. Winter 2005-2006. Accessed September 2019

10. Intercollegiate Horse Show Association. 2018-2019 IHSA Rulebook. Intercollegiate Horse Show Association. 2019. Accessed September 2019
11. Nelson DE, Pivara FP, Condie C, Smith SM. Injuries in Equestrian Sports. Phys Sportsmed. 1994: 22 (10); 53-60. https://doi.org/10.1080/00913847.1994. 11710501.

12. National Collegiate Equestrian Association. Rulebook. National Collegiate Equestrian Association, Waco, TX. 2019.

13. National Collegiate Athletic Association. NCAA Interassociation Consensus: Diagnosis and Management of Sport-Related Concussion Practices. Sport Science Institute, National Collegiate Athletic Association, Indianapolis, IN. 2017. Available at: https://www.ncaa.org/sites/default/files/SS I ConcussionBestPractices 20170616.pdf. Accessed September 2019. 


\section{APPENDIX A: Return-To-Ride Protocol}

Management of a concussion in sport can be challenging, as there are no universal standards on concussion care and return to play guidelines. The following document is a concussion policy and management plan that specifically outlines the role of the Sweet Briar College Sports Medicine health care providers. The goal of this protocol is to give athletic trainers and physicians dealing with concussions a common student-athlete concussion management program.

This policy is for the concussion care and management of student-athletes in the competitive programs of SWEET BRIAR COLLEGE Athletics and Riding. The Sports Medicine staff will provide concussion healthcare through baseline testing, education, injury diagnosis, management and rehabilitation. In order to return to participation, the studentathlete must complete the Return to Learn and Return to Play/Ride protocols through the Sports Medicine staff and be cleared to return to participation by the Team Physician or their designee.

\section{Education}

SWEET BRIAR COLLEGE will present all student-athletes with the NCAA Concussion Fact Sheet for StudentAthletes. Student-athletes are required to sign a Student-Athlete Acknowledge Statement annually stating that they received, read and understand the NCAA Concussion Fact Sheet. This document on concussions includes the definition of a concussion, how to reduce the risk of concussions, symptoms of concussions, and how to report any concerns for themselves or a teammate regarding a concussion. Student-athletes are required to attend a preseason brief session with the athletic trainer prior to participation. Concussion education is also included in this meeting.

Coaches at SWEET BRIAR COLLEGE will receive the NCAA Concussion Fact Sheet for Coaches annually. They are required to sign the Coach Acknowledge Statement annually prior to the start of their season. Additional educational opportunities in relation to concussions is available upon request, as needed and/or when new information regarding concussions becomes available.

Members of the Sports Medicine staff will receive a copy of the NCAA Concussion Fact Sheet for Coaches and Student-Athletes annually to have as reference. In addition, all members of the Sports Medicine staff will participate in concussion education annually including a review of the concussion management policy during the Emergency Action Plan annual review.

\section{Baseline Testing}

Upon enrollment at SWEET BRIAR COLLEGE and before the first day of practice/tryouts, every student-athlete will undergo baseline testing. Baseline testing must occur annually prior to the student-athlete's first day of their first season for the academic year. If a student-athlete sustains a concussion during the academic year, a new baseline will be completed prior to their return to participation. In compliance with the Arrington Settlement and as 
recommended by the NCAA, and the SWEET BRIAR COLLEGE Athletic Conference the baseline assessment for all SWEET BRIAR COLLEGE student-athletes will consist of the following:

- Sport Concussion Assessment Tool- 5th Edition (SCAT5)

- Balance Error Scoring System (BESS) Test

- ImPACT Computerized Concussion Test (Baseline)

\section{Concussion}

The SWEET BRIAR COLLEGE Sports Medicine Staff will determine whether or not a concussion has occurred, realizing that each concussion and each student-athlete is different, and individual treatment plans are necessary. A concussion is a brain injury that may be caused by a blow to the head, face, neck or elsewhere on the body from an impulsive force transmitted to the head. Concussions can also be a result from contact with another player, hitting a hard surface such as the ground, or being hit by a piece of equipment such as a bat, basketball or softball. A concussion may present differently from one student-athlete to another.

\section{A concussion can happen even if the athlete DOES NOT lose consciousness.}

Following a concussion, a student-athlete may exhibit the following signs and symptoms:

\begin{tabular}{|l|l|l|}
\hline Physical Symptoms & Cognitive Symptoms & Emotional Symptoms \\
\hline Headache & Memory Loss & Irritability \\
Vision Difficulty & Attention Disorders & Sadness \\
Nausea and/or Vomiting & Concentration Problems & Nervousness \\
Dizziness and/or Lightheadedness & Confusion & Sleep Disturbances \\
Balance Difficulties & Disorientation & Personality Changes \\
Light Sensitivity & & Feeling of Being Stunned \\
Noise Sensitivity & & Depression \\
Fatigue & & \\
Slurred/Incoherent Speech & & \\
Ringing in the Ears & & \\
Loss of or Altered Consciousness & & \\
Vacant Stare & & \\
Loss of Bowel Control & & \\
Loss of Bladder Control & & \\
Seeing Bright Lights or Stars & & \\
\hline
\end{tabular}

When a student-athlete exhibits signs, symptoms or behaviors consistent with a possible concussion, they shall be removed from practice or competition and evaluated by the Certified Athletic Trainer and/or Team Physician. Signs and symptoms of a concussion can take up to seven (7) days to present fully. It is important that student-athletes be truthful and forthcoming about signs and symptoms of a concussion as soon as they present. The student-athlete will be evaluated and monitored to determine their status as it relates to being concussed. Once a student-athlete has been diagnosed with having a concussion, they shall be removed from physical activity for the remainder of that day, and not allowed to participate in 
academic activities for the remainder of that day. The student-athlete, or their parent, guardian or roommate (as needed depending on the needs and requests of the student-athlete), will be provided with instructions on further care and the Home Concussion Information Sheet upon discharge.

The student-athlete will be monitored for progression of symptoms during the ongoing course of their concussion by the SWEET BRIAR COLLEGE Sports Medicine Staff. Immediately following injury, the studentathlete will be placed on cognitive brain rest for 24-48 hours unless noted by the athletic trainer and/or team physician. The SWEET BRIAR COLLEGE Sports Medicine Staff will use the SCAT5 and BESS tests daily, along with other examinations deemed necessary during the evaluation of the concussed studentathlete until the symptoms have subsided and/or have been resolved. All of these evaluations will be compared to the baseline scores of the student-athlete and will aid in the Return to Learn and Return to Play/Return to Ride progressions.

Once the student has sustained a concussion, the athletic trainer will set up an appointment for evaluation with the team physician during their the next sports medicine clinic day. When the student-athlete is either approaching the end of Return to Learn Phase 1 or enters Return to Learn Phase 2, the athletic trainer will notify the Director of Academic Resource Center so they can arrange a meeting with the student-athlete to create a plan for post-injury academic success.

With permission for release of information from the student-athlete, the Academic Resource Center will be notified and updated on the condition of the student-athlete after they suffer a concussion in order for the Dean's Office to notify professors. Notifications include:

- The Office of the Dean (Dean and Secretary)

- Team Physician

- Dean of Students

- Director of the Academic Resource Center

- Athletic Director

- Riding Director (in the event the injured student-athlete is on an equestrian team)

- Head Coach(es) of the team(s) the injured student-athlete is a member of

The Dean of Students, the Office of the Dean and Director of the Academic Resource Center will be notified during the student-athlete's Return to Learn protocol. Once the student-athlete progresses out of Return to Learn and into Return to Play and/or Return to Ride, they will no longer receive email updates as the student will be returned to full academic participation at this point.

Student-athletes will complete the ImPACT test as part of their concussion recovery plan. They will take the test a total of three times: 48 hours post-injury, at the completion of Return to Learn phase 4 (RTL 4) and at the completion of Return to Play day 5 (RTP 5) or Return to Ride day 7 (RTR 7). 
It is important to note that all Return-to-Learn, Return-to-Play, Return-to Ride, and Return-to-Play/Returnto-Ride Combination protocols are individualized on a case-by-case basis, allowing for the student-athlete to receive the best available and most accurate care to aid in their recovery.

\section{Return to Learn (RTL)}

The SWEET BRIAR COLLEGE Athletic Training Staff, Team Physicians, and the Academic Resource Center will work together to determine Return to Learn status of a post-concussed student-athlete. The Office of the Academic Dean will inform the student-athlete's professors and any accommodations that may be necessary in their return to the classroom and activities that are associated with their full academic return.

Once a student-athlete has been diagnosed with having a concussion, they shall be removed from physical activity for the remainder of that day and not allowed to participate in academic activities. The Office of the Academic Dean will be notified of the status of the student-athlete.

Following a concussion, the student-athlete will be seen daily by a SWEET BRIAR COLLEGE Athletic Training Staff member prior to the start of their first academic class. At that time, the decision will be made if the student-athlete's symptoms have progressed to allow them to attempt to attend class, study hall, and tutoring sessions that day. The Office of the Academic Dean will then convey the status of the studentathlete to their professors. If a student-athlete is allowed to return to class, they will be evaluated that afternoon in order to complete an updated SCAT5, to aid in determining how the day of learning progressed. This is repeated until the student-athlete successfully completes RTL 4 ; then they will be seen once per day until the completion of their designated return to participation protocol.

\section{Guidelines for Progression}

- Student-athlete proceeds to the next level only if asymptomatic at the current level of progression.

- Following a recovery phase, if they are symptom-free for 24 hours they will progress to the next level.

- If symptoms occur, they rest until they are symptom-free and return to the previous stage that did not produce symptoms.

- During recovery, it is important for the student-athlete's work and assignments to be prioritized so they can make up all missed work without inducing additional stress and emotional distress.

- Phases of Recovery

- Phase 1: Complete Physical and Cognitive Rest

- No school attendance

- Strict limitations on technology usage and reading

- Rest

- Phase 2: Return to School with Academic Accommodations

- Initiated once student-athlete reports four or less symptoms with a total severity score of four or less

- Continue limits on technology usage 
- Avoid heavy backpacks

- No tests/exams/quizzes/reading/homework, athletics, band or chorus

- Monitor symptoms

- Rest at home

- Phase 3: Continue Academic Accommodations

- Attend school full-time if possible

- Increase workload gradually (testing, homework, etc)

- Monitor symptoms

- Rest at home

- Phase 4: Full Return to Academics

- Attend school full-time

- Self-advocate at school (meet due dates, etc)

- Resume normal activities

In any concussion case when a student-athlete needs or requests counseling, the Sports Medicine Staff will assist in referring them to a Counselor, located at on the second floor of Protho Hall in Student Life.

\section{Return to Play (RTP)}

The gradual exertion return to play process is designed to allow for a gradual increase in exercise volume and intensity during the return to play process.

\section{Guidelines for Progression}

- Student-athlete proceeds to the next level only if asymptomatic at the current level.

- If symptoms occur during activity: Stop activity, rest for 24 hours and begin at the previous level that did not produce symptoms.

- Levels of Progression

- Phase 1: Light aerobic exercise

- 20 minutes stationary bike at $70 \%$ maximum heart rate

- Phase 2: Moderate aerobic exercise

- Interval bike ride: 10 sets of 30 second sprints/30 seconds recovery

- Body weight circuit: Squats/Push-Ups/Sit-Ups: Three sets of 20 each

- Phase 3: Sport-Specific Exercises

- 60 yard shuttle run

- Plyometric Circuit (examples): 10 yard bounding/10 medicine ball throw/10 vertical jumps; three times each

- 15 minutes of sports-specific non-contact drills

- Phase 4: Full-contact practice

- Limited participation in full contact practice and monitoring of symptoms

○ Phase 5: Full Participation in Practice

\section{Return to Ride (RTR)}


The gradual exertion return to ride process is designed to allow for a gradual increase in exercise volume and intensity during the return to ride process.

\section{Guidelines for Progression}

- Student-athlete proceeds to the next level only if asymptomatic at the current level.

- If symptoms occur during activity: Stop activity, rest for 24 hours and begin at the previous level that did not produce symptoms.

- Due to the nature of the aerobic and anaerobic demands of the sport of equestrian, each phase increases in the demand of those systems on the body during sport-specific controlled activity.

- Levels of Progression

O Phase 1

- Mount/Dismount, lead for five minutes (Complete two times)

- Mount, walk undersaddle for 15 minutes

- Dismount and put the horse away

○ Phase 2

- Mount and walk for 10 minutes

- Trot two laps around the indoor arena

- Walk five minutes

- Trot two laps around the indoor arena

- Walk for 10 minutes

- Dismount and put the horse away

○ Phase 3

- Mount and walk for 10 minutes

- Trot four laps around the indoor arena

- Walk two minutes

- Trot four laps around the indoor arena

- Walk for 10 minutes

- Dismount and put the horse away

- Phase 4

- Mount and walk for 10 minutes

- Trot four laps around the indoor arena

- Walk two minutes

- Trot four laps around the indoor arena

- Walk for one minute

- Canter a lap in each direction

- Walk for 10 minutes

- Dismount and put the horse away

○ Phase 5

- Mount and walk for 10 minutes

- Work at the trot and canter for 15 minutes with periods of walk

- Finish with walk for 10 minutes

- Dismount and put the horse away

- Phase 6

- Repeat Phase 5

- Add jumping small obstacles

O Phase 7

- Full participation in practice or lesson without restrictions 


\section{Return to Play/Return to Ride Combination}

In the case of students who are both considered student-athletes for both an NCAA team and a competitive equestrian team, they will complete a combination of the Return to Play and Return to Ride protocols. Completion of this combination protocol will be considered sufficient in allowing them to return to both activities. This protocol is a guideline and can be adjusted by the Director of Sports Medicine and designated Team Physician to best accommodate the recovery of the student-athlete and their participation schedules.

- Student-athlete proceeds to the next level only if asymptomatic at the current level.

- If symptoms occur during activity: Stop activity, rest for 24 hours and begin at the previous level that did not produce symptoms.

- Levels of Progression

- Phase 1: Return to Ride Phase 1

- Mount/Dismount/Lead in Hand/Walk Undersaddle

- Mount/Dismount, lead for five minutes (Complete two times)

- Mount, walk undersaddle for 15 minutes

- Dismount and put the horse away

- Phase 2: Return to Play Phase 2

- Interval bike ride: 10 sets of 30 second sprints/30 seconds recovery

- Body weight circuit: Squats/Push-Ups/Sit-Ups: Three sets of 20 each

- Phase 3: Return to Play Phase 3

- 60 yard shuttle run

- Plyometric Circuit (examples): 10 yard bounding/10 medicine ball throw/10 vertical jumps; three times each

- 15 minutes of sports-specific non-contact drills

- Phase 4: Return to Ride Phase 5

- Mount and walk for 10 minutes

- Work at the trot and canter for 15 minutes with periods of walk

- Finish with walk for 10 minutes

- Dismount and put the horse away

- Phase 5: Return to Play Phase 5

- Full Participation in Practice

- Phase 6: Return to Ride Phase 6

- Repeat Phase 5

- Mount and walk for 10 minutes

- Work at the trot and canter for 15 minutes with periods of walk

- Finish with walk for 10 minutes

- Dismount and put the horse away

- Add jumping small obstacles

- Phase 7: Return to Ride Phase 7

- Full participation in practice or lesson without restrictions

No student-athlete will be allowed to return to full activity or competition until they are asymptomatic in limited, controlled, and full-contact activities. Any student-athlete diagnosed with a concussion must be medically cleared by a Team Physician before returning to 
competition. This includes any student-athlete who arrives to SWEET BRIAR COLLEGE with a pre-existing concussion, and/or have continuing symptoms from a resolved concussion.

The Return-to-Learn, Return-to-Play, Return-to-Ride and Return-to-Play/Return-to-Ride Combination protocols are different and can be completed at different times. Return-to-Learn will be initiated before Return-to-Play, Return-to-Ride and Return-to-Play/Return-to-Ride Combination. They can also occur simultaneously. For student-athletes who also participating in the Equestrian Program, they must complete the Return-to-Play/Return-to-Ride Combination protocol. It is important to note that the listed progression timelines can take place over a period of days, weeks, or months. It could potential result in medical disqualification from participation in SWEET BRIAR COLLEGE Athletics and Equestrian for a season or indefinitely.

\section{Athletes with Multiple Concussions}

The SWEET BRIAR COLLEGE Athletic Training Staff and team physicians have the right to review all student-athlete's medical history, both previous and current, and reserve the right to withhold from participating in college sponsored athletic events (i.e., practices, game, weight-lifting, conditioning, shows, competitions, travel, etc).

\section{Travel with Athletes Recovering from a Concussion}

The ability of a student-athlete recovering from a concussion to travel to athletic or equine competitions or trainings with their team is at the discretion of the SWEET BRIAR COLLEGE Athletic Training and Sports Medicine Staff. The SWEET BRIAR COLLEGE Athletic Training Staff and team physicians have the right to forbid travel for a student-athlete recovering from a concussion until they are cleared for full athletic, equine and academic participation.

\section{Returning to Work}

In the case that a student-athlete sustains a concussion, they will be recommended to refrain from work (on or off campus) while in the initial phases of recovery. Once a student-athlete has completed Return to Learn Phase 4 (RTL 4), they can consider returning to work. If a student-athlete is on work-study at the College, a member of the Human Resources team will be put on the student-athlete's release and notified of the student-athlete's injury as well as when they are permitted to return to work.

\section{Returning to Drive}

When a student-athlete sustains a concussion, they be recommended to refrain from driving a motorized vehicle. This includes but it not limited to a car, trunk, motorcycle, motorized scooter, gator, golf cart. They will also be recommended to refrain from riding in a motorized vehicle driven by another person, unless in 
the case of an emergency. Once a student-athlete completes Return to Ride or Return to Play Day 3 (RTR 3 or RTP 3), they consider returning to driving and riding in motorized vehicles.

\section{Annual Review}

In accordance with the NCAA, this policy will be reviewed annually by the institution's athletic health care administrator (AHCA). The AHCA is a designated health provider within the athletic department who oversees the administration and delivery of healthcare for the institution's student-athletes. 